\title{
Title: Efficacy of transdermal delivery of liposomal micronutrients through body oil massage on neurodevelopmental and micronutrient deficiency status in infants: Results of a randomized placebo controlled clinical trial
}

Aditi Apte ( $\nabla$ aditi.apte@kemhrcvadu.org)

KEM Hospital Research Centre

\section{Mudra Kapoor}

Indian Institute of Technology Bombay

Sadanand Naik

KEM Hospital

Himangi Lubree

KEM Hospital Research Centre

Pooja Khamkar

KEM Hospital Research Centre

Diksha Singh

KEM Hospital Research Centre

Dhiraj Agarwal

KEM Hospital Research Centre

\section{Sudipto Roy}

KEM Hospital Research Centre

Anand Kawade

KEM Hospital Research Centre

\section{Sanjay Juvekar}

KEM Hospital Research Centre

\section{Rinti Banerjee}

Indian Institute of Technology Bombay

\section{Ashish Bavdekar}

KEM Hospital Research Centre

\section{Research Article}

Keywords: anemia, body massage, fortification, iron, vitamin D 
Posted Date: August 11th, 2021

DOl: https://doi.org/10.21203/rs.3.rs-394886/v1

License: (c) (i) This work is licensed under a Creative Commons Attribution 4.0 International License. Read Full License 


\section{Abstract}

Background: Micronutrient deficiency is a known cause of adverse neurodevelopment and growth. Poor adherence to oral regimes of micronutrient supplements is a known challenge during the implementation of supplementation programs. The present study evaluates the benefits of liposomal encapsulated micronutrient fortified body oils (LMF oil) that can be used for infant body massage in terms of neurodevelopment and prevention of deficiency.

Study design: Double-blind randomized clinical trial

Methods: 444 healthy infants aged 4-7weeks were randomized to receive either LMF oil (containing iron, vitamin D, folate, and vitamin B12) or placebo oil for gentle body massage till 12months of age. Blood samples were collected at 6 and 12 months for transferrin saturation (TSAT), hemoglobin, and 25hydroxy vitamin (25-OH-D) levels. Mental and motor development was assessed at 12 months using developmental assessment for Indian Infants (DASII).

Results: A total of 391 infants completed the study. There was no significant improvement in the hemoglobin in the intervention group at 12 months of age as compared to the placebo group [-0.50 vs.-0.54 gm\%]. There was a marginally significant improvement in 25-OH-D at 12 months in the LMF oil group [ $+1.46 \mathrm{vs} .-0.18 \mathrm{ng} / \mathrm{ml}, \mathrm{p}=0.049$ ]. In the subgroup of infants with moderate anemia, the intervention prevented the decline in hemoglobin at 12 months of age [adjusted mean change $+0.11 \mathrm{vs} .-0.51 \mathrm{gm} \%$, $p=0.043]$. The mental or motor developmental quotients in the intervention group were not significantly different from those in the placebo group.

Conclusion: Use of LMF oil for prevention of nutritional deficiency did not offer significant protection against nutritional anemia but prevented vitamin D deficiency to some extent with improvement in $25-\mathrm{OH}-$ $\mathrm{D}$ at 12 months. In the subgroup of infants with moderate anemia, the intervention prevented the decline in hemoglobin at 12 months of age. The intervention did not result in significant improvement in mental or motor development. Further evaluation with increased doses needs to be undertaken.

Trial registration: CTRI no: CTRI/2017/11/010710; dated 30/11/2017

[http://ctri.nic.in/Clinicaltrials/advancesearchmain.php ]

\section{Introduction}

Early childhood is a critical period for growth and neurodevelopment(1). There is compelling evidence that iron deficiency during 6-24 months of age is associated with poor cognitive, motor, and socioemotional development(2). Folate, known to have a role in neural tube development, and vitamin B12, known to affect myelination and methionine synthesis, are important micronutrients for brain development(3-5). There is upcoming evidence on the benefits of vitamin D in neurodevelopment apart 
from its effect on bone and calcium metabolism(6). Despite this, there is inconsistent evidence from randomized controlled studies on whether supplementation of one or more of these nutrients can result in improved neurodevelopment (7)(8).

Potential for improved neurodevelopment is one of the important rationales behind the introduction of iron-folate supplementation in public health programs and despite the presence of these programs, $59 \%$ of under-five children in India suffer from nutritional anemia(9). Vitamin D deficiency has been documented in up to $80 \%$ of the Indian population of all ages (10). Poor adherence to dosage regimes due to forgetfulness of the mothers, fear of side effects like gastritis, especially for iron supplements, poor coverage, and lack of knowledge are known challenges in the implementation of supplementation programs (11-13). A small amount of orally administered iron is absorbed, and the unabsorbed iron is associated with adverse effects such as gastritis and increased risk of gastrointestinal infections $(14,15)$.

Transdermal route is an alternate non-invasive route for the administration of nutrients and drugs with gastrointestinal intolerability and offers higher surface area and may offer better compliance as compared to the oral route. Although there are a few molecules that can favorably cross the intact skin barrier, active and passive technologies can potentially improve transdermal absorption of several molecules(16-20). We developed an innovative formulation of body oil containing soya phosphatidylcholine and oleic acid-based liposomes encapsulating iron, folate, vitamin B12, and vitamin D using a patented platform for increased permeation across the stratum corneum barrier $(21,22)$. The liposomes showed high permeation through the stratum corneum and showed $40-50 \%$ encapsulation efficiency for ferrous bisglycinate, $20-40 \%$ for folate and B12, and $90-95 \%$ for vitamin D. The technology has demonstrated safety and efficacy in in-vitro and in-vivo animal models for transdermal delivery of nutrients at supplemental doses(23). The technology was also found to be non-irritant in healthy human volunteers and children (24)(25).

This technology was used to fortify body oil to be used for infant massages. Infant oil massage is an ancient practice in the Indian subcontinent with some benefits for growth and development and has widespread cultural as well as social acceptance(26). A formative research study conducted before the clinical study within the study area showed that infant oil massage was a routine practice in more than $90 \%$ of households and there was a readiness to accept fortified oil(23). Thus fortifying the body oil with nutrients can potentially improve the compliance and acceptability of the intervention.

This paper describes a proof of concept evaluation of this liposomal micronutrient fortified oil (LMF oil) in healthy infants from rural India. The objectives of the study were to assess whether the use of LMF oil for gentle body massage during infancy results in improved neurodevelopment with reduced risk of nutritional deficiency at the end of one year.

\section{Methods}

\section{Study design and settings}


This was a randomized, double-blind, placebo-controlled parallel-group clinical study that was conducted between February 2018 to September 2019 at Vadu Rural Health Program of Kind Edward Memorial (KEM) Hospital Research Centre, Pune, India. (24).

\section{Approvals}

The study was approved by the institutional ethics committee of KEM Hospital Research Centre (KEMHRC/LFG/EC/146) and the Health Ministry Screening Committee of India. The study was registered at the clinical trial registry of India (CTRI no: CTRI/2017/11/010710, dated 30/11/2017 accessed at http://ctri.nic.in/Clinicaltrials/advancesearchmain.php).

\section{Study population}

Healthy infants born at full term aged between 4 to 7 weeks with a birth weight of at least $2 \mathrm{~kg}$ were approached for recruitment in the study from the study population at Vadu Rural Health Program (VRHP). VRHP is a community-based program for research and health care delivery by KEM Hospital research centre, Pune, India, and is functional across 22 villages in Western Maharashtra. The population is mainly rural with agriculture as their main occupation. Demographics of this population are regularly monitored through health and demographic surveillance (HDSS) conducted by VRHP(27). Based on the HDSS data, antenatal care data from the public and private health facilities and the number of births within Vadu HDSS area were tracked and potential study participants were enumerated. Written informed consent was taken from the parents of eligible infants and those willing to participate were enrolled in the study. Major exclusion criteria included generalized skin disorder or skin infection, major congenital anomalies, major birth or neonatal complications, and severe malnourishment (weight for age z-score <-3.0). Families who were not planning to relocate for at least one year were included in the study.

\section{Preparation of the used oil}

The formulation of LMF oil was developed initially by Banerjee et al at the Indian Institute of Technology, Mumbai, India. The technology was licensed to KEM Hospital Research Centre Vadu for non-commercial use and Murli Krishna Pharmaceuticals Ltd. for manufacturing and commercialization. The LMF oil contained sunflower oil fortified with liposomal encapsulated ferrous bisglycinate, vitamin B12, folic acid, and vitamin D. Sunflower oil was used as a base as it is a rich source of essential fatty acids(28). The micronutrients were added as per their recommended dietary allowance for the given age $(29,30)$.

Ferrous bisglycinate was procured from Puneet Laboratories, Mumbai, India and vitamin B12, folate, and vitamin D were procured from SRL Chemicals Pvt Ltd, Mumbai, India. Soya lecithin and Oleic acid were procured from Hi-Media. The liposomes of the nutrients were prepared using generally recognized as 
safe (GRAS) materials without using any organic solvents. The liposomal oils were manufactured by Murli Krishna Pharma Pvt Ltd, Ranjangaon, Pune under EuGMP conditions.

Two strengths of the test oil were developed for age groups 1-6 months and 6-12 months respectively to match their dietary requirements of individual nutrients [Additional table1]. The technology was earlier tested for its safety and efficacy through in-vitro and in-vivo studies for transdermal delivery of supplemental doses of nutrients(23) [Additional table 2]. The process of development of the LMF oil as a study intervention has been described earlier(24).

The placebo oil was an identical-looking product containing sunflower oil which was fortified with empty liposomes (not containing micronutrients) and was identical in appearance and smell to that of the test oil. Both the formulations were stable at room temperature when kept away from sunlight for at least 3 months.

\section{Study procedures}

After enrollment, the infants were randomized in a 1:1 ratio to receive either LMF oil or placebo oil using computer-generated block randomization. To minimize the selection bias, allocation concealment was done by using sequentially numbered opaque envelopes.

The caregivers from both groups were trained for gentle massage of a fixed amount of the study oil (LMF oil or placebo oil, $2.5 \mathrm{ml}$ ) on the skin avoiding contact with mucosal surfaces, face, neck, and scalp. The volume of oil application was decided based on a pilot study conducted to assess the adequate amount of sunflower oil for infants of various ages (24). The caregivers were informed regarding the health benefits of gentle oil massage in infants to ensure good compliance to intervention. They were instructed to use the study oil at night before bedtime to allow optimum absorption of the study oil. Monthly supplies of oil bottles were provided through home visits by the field research assistants and compliance was monitored through compliance cards and calculation of used oil bottles.

Data collection was done at baseline, 6 and 12 months through clinic visits. At baseline, demographic details, birth history, maternal socioeconomic status were collected. Anthropometric parameters (weight, length, and head circumference) were measured using standardized procedures. Information about breastfeeding and weaning was collected at each clinic visit. Details about any concomitant medicines including iron or vitamin supplements and adverse events were collected during routine fortnightly field visits by the field research assistants.

All the study participants underwent neurodevelopmental assessment using a developmental assessment scale for Indian infants (DASII) at 12 months by a trained clinical psychologist. DASII is an Indian modification of the Bayley scale for infant development containing mental (163 items) and motor (67 items) scales and can be used to assess mental and motor developmental quotient in infants aged up to 30 months(31). The assessor was blinded to the allocation of groups. 
Tolerability of the study oils was assessed using the standard skin scoring system for irritation which grades the presence of erythema and dryness during clinic visits(32). All the caregivers were given appropriate nutritional advice during clinic visits and children with unresolved anemia or vitamin $D$ deficiency were treated with oral iron and vitamin D supplements at the end of the study.

\section{Laboratory procedures}

At 6 and 12 months, $5 \mathrm{ml}$ of non-fasting venous blood samples were collected into evacuated tubes containing EDTA and trace element-free tubes containing no coagulant (BD Vacutainer). Blood in the EDTA tubes was immediately used for assessment of hemoglobin $(\mathrm{Hb})$ concentrations and red blood cell on cell analyzer at the research laboratory at VRHP with appropriate quality control and standard procedure. The trace element-free tubes were centrifuged at $3000 \mathrm{rpm}$ for $15 \mathrm{mins}$ at $4^{0} \mathrm{C}$, and serum was separated, aliquoted, and stored at $-80^{\circ} \mathrm{C}$ till further analysis. The serum samples were transported in cooling boxes with ice packs to the biochemistry laboratory at KEM Hospital, Pune in batches for assessment of transferrin saturation (TSAT) and 25-hydroxy vitamin (25-OHD) levels.

Complete blood counts were assessed using a duly calibrated Medionic M3 auto-analyser. Iron and total iron-binding capacity (TIBC) estimations were done using the Ferrozine method on Cobas-Integra 400plus analyser(33). The inter-and intra-batch coefficient of variations for Iron were $3.4 \%$ and $3.0 \%$ respectively and for TIBC were $5.7 \%$ and $5.1 \%$ respectively. TSAT was calculated as serum iron divided by TIBC.

Serum 25-OHD estimation was done using chemiluminescent microparticle immunoassay technique on Architect ci4000 Chemistry analyser (Abbott)(34). The inter- and intra-batch coefficients of variations for vitamin $D$ were $7.2 \%$ and $6.6 \%$ respectively.

\section{Data management and quality control}

The data were collected on paper case record forms and were then entered in electronic case record forms using Open Clinica community edition software after source data verification. The data entered into the electronic case record form (eCRF) were checked for completeness and quality assurance. The anonymized dataset was extracted for analysis following source data verification. The dataset was archived at a local server at VRHP.

\section{Sample size calculation and data analysis}

The primary outcome for the study was a neurodevelopmental assessment using DASII. Hence, sample size calculation was based on the assumption that the intervention would improve the developmental quotient on DASII by at least a score of 5 . Considering a standard deviation of 15 for DASIl score, alpha error of $5 \%$, and power of 90 , sample size of 189 was required in each group. Considering a dropout rate 
of $15 \%$, the sample size of 222 in each arm was selected. This sample size was adequate to detect a $27 \%$ reduction in the prevalence of anemia in the test group considering $60 \%$ prevalence of anemia in the placebo group and $20 \%$ reduction in the prevalence of vitamin $D$ deficiency considering vitamin $D$ deficiency $(<20 \mathrm{ng} / \mathrm{ml})$ in $75 \%$ of the participants in the placebo group at $90 \%$ power and $5 \%$ alpha error.

The data analysis was done on an intention-to-treat basis. Parameters were expressed as the mean and standard deviation for normally distributed variables and median with interquartile range for nonparametrically distributed variables. Normally distributed variables were compared using an unpaired ttest with unequal variance. For data not normally distributed even after square root transformation, nonparametric tests were used. Proportions were compared between the groups by using the Chi-square test.

Linear regression models were used for calculating treatment effect in terms of the mental and motor developmental quotient, change in hemoglobin, change in 25-hydroxy vitamin $D$ levels, and change in transferrin saturation levels between the two groups while adjusting for compliance and concomitant medications. Additionally, multiple logistic regression analysis was done to compare the effect of the intervention on subgroups of motor and mental developmental quotient (DQ) basing the categories on the $50^{\text {th }}$ centile. In addition to adjustment for compliance to intervention and concomitant nutritional supplements, the subgroup analyses were adjusted for gender, weaning age, and maternal education. All the analyses were done using STATA version 15.0.

\section{Results}

Of the total 489 children aged 4-7 weeks of age screened at baseline, 45 children failed to meet eligibility criteria. Total 444 children were randomly assigned to the study groups. At 6 months, 405 children completed clinic visit with attrition rate of $9.45 \%(n=21)$ in test and $8.11 \%(n=18)$ in placebo group $(p=0.62)$. At 12 months, a total of 391 children completed the study with an overall attrition rate of $14.4 \%$ in the test group and $9.45 \%$ in the placebo group $(p=0.94)$. The reasons for loss to follow-up mainly included outmigration and consent withdrawals [Figure 1].

Baseline demographic information including maternal characteristics is given in table 1 . All the demographic parameters and birth, as well as maternal characteristics, were comparable between the groups except that the body weight was more in the LMF oil group. In both the groups, about $65 \%$ of the children were born vaginally and $13-16 \%$ of the children were born with low birth weight $(<2.5 \mathrm{~kg})$. The average maternal age was $24 \mathrm{yrs}$; more than $95 \%$ of the mothers received some school education and $93 \%$ of them were homemakers.

Table 1: Baseline demographic information of the study participants ${ }^{\#}$ 


\begin{tabular}{|c|c|c|}
\hline & $\begin{array}{l}\text { LMF oil } \\
(n=222)\end{array}$ & $\begin{array}{l}\text { Placebo oil } \\
(n=222)\end{array}$ \\
\hline Age in days $\$$ & $35.59 \pm 5.86$ & $37.51 \pm 6.14$ \\
\hline Sex, number of females & $97(43.69)$ & 107(48.20) \\
\hline Weight in kg* & $3.97 \pm 0.52$ & $3.88 \pm 0.49$ \\
\hline Length in $\mathrm{cm}$ & $54.60 \pm 2.15$ & $54.47 \pm 2.37$ \\
\hline Head circumference in $\mathrm{cm}^{\$}$ & $35.95 \pm 1.48$ & $35.88 \pm 1.46$ \\
\hline Low birth weight & $29(13.06)$ & $37(16.66)$ \\
\hline \multicolumn{3}{|l|}{ Mode of delivery } \\
\hline Vaginal & $146(65.77)$ & 146(65.77) \\
\hline Caesarean section & $76(34.23)$ & $76(34.23)$ \\
\hline Exclusively Breastfed & 212(95.50) & 215(96.85) \\
\hline \multicolumn{3}{|l|}{ Birth order } \\
\hline First & $65(29.28)$ & $73(32.43)$ \\
\hline Second & $88(39.64)$ & 87(39.19) \\
\hline Third & $45(20.27)$ & $49(22.07)$ \\
\hline Fourth & 20(09.01) & $9(4.05)$ \\
\hline Fifth or more & $4(1.80)$ & $5(2.25)$ \\
\hline Maternal age in years $\$$ & $24.30 \pm 3.79$ & $24.34 \pm 3.79$ \\
\hline \multicolumn{3}{|l|}{ Maternal education } \\
\hline Illiterate & $4(1.8)$ & $9(4.05)$ \\
\hline Primary education & $46(20.72)$ & $52(23.42)$ \\
\hline Secondary education & $59(26.58)$ & $50(22.52)$ \\
\hline Higher secondary education & $76(34.23)$ & $58(26.13)$ \\
\hline Graduate & $31(13.96)$ & $48(21.17)$ \\
\hline Postgraduate & $6(2.7)$ & $6(2.7)$ \\
\hline \multicolumn{3}{|l|}{ Maternal occupation } \\
\hline Homemaker & 208(93.69) & $208(93.24)$ \\
\hline Agriculture & $5(2.25)$ & $6(2.70)$ \\
\hline
\end{tabular}




\begin{tabular}{|lll|}
\hline Student & - & $1(0.45)$ \\
\hline Industry & - & $3(1.35)$ \\
\hline Others & $9(4.05)$ & $5(2.25)$ \\
\hline
\end{tabular}

Unpaired t-test used for comparison of normally distributed variables; Pearson chi2 for frequencies \# Values are expressed as mean +/- SD for continuous data and n(\%) for categorical data ${ }^{*} p=0.03 ; \$$ Variables not normally distributed; Kolmogorov Smirnoff test used for comparison More than $90 \%$ of the participants in both the groups had compliance to the intervention of more than $80 \%[$ Additional figure1]. Compliance with the intervention was comparable between the groups at 6 months and 12 months.

Based on the data about concomitant medications received during study duration, $14(7.36 \%)$ and $9(4.47 \%)$ children from the LMF oil and placebo group respectively received health supplements containing iron for at least 1 month during the study period. On the other hand, $103(54.21 \%)$ and 112 $(55.72 \%)$ children in the LMF oil and placebo group respectively received additional vitamin $D$ supplementation for at least one month. These values were not significantly different between the two groups.

There was a mean hemoglobin reduction of $0.5 \mathrm{gm} \%$ in the LMF oil group at 12 months which was comparable to that in the placebo group $(0.54 \mathrm{gm} \%$ ) [Table 2 \& Figure 3a]. Overall, the proportion of anemia $(\mathrm{Hb}<11 \mathrm{gm} / \mathrm{dl})$ increased at 12 months as compared to 6 months without any significant difference between the study groups [Table 2]. As compared to 6 months, there was a $7.38 \%$ and $11.2 \%$ increase in anemia in LMF oil and placebo groups respectively at 12 months of age. [Figure 2a]. In the subgroup of children with moderate anemia at 6 months, the intervention of LMF oil prevented the reduction in hemoglobin at 12 months as compared to the placebo group [0.11 gm\% increase in LMF oil group vs. $0.51 \mathrm{gm} \%$ reduction in the placebo group, $p=0.043$ ]. None of the children had severe anemia at 6 or 12 months. There was a reduction in transferrin saturation levels in both the groups at 12 months as compared to 6 months without any significant intergroup difference [-2.36\% in LMF oil groups Vs. -2.10 in placebo].

Table 2: Changes in the hematological and biochemical parameters $\$$ 


\begin{tabular}{|c|c|c|c|c|c|c|c|}
\hline & \multicolumn{3}{|c|}{ LMF oil } & \multicolumn{3}{|c|}{ Placebo oil } & \multirow{2}{*}{$\begin{array}{l}\text { Treatment } \\
\text { effect } \\
(95 \% \mathrm{Cl})\end{array}$} \\
\hline & $\mathbf{N}$ & Value & $\begin{array}{l}\text { Adjusted } \\
\text { mean } \\
\text { change* }\end{array}$ & $\mathbf{N}$ & Value & $\begin{array}{l}\text { Adjusted } \\
\text { mean } \\
\text { change* }\end{array}$ & \\
\hline \multicolumn{8}{|c|}{ Changes in hemoglobin (Hb) levels, gm\% } \\
\hline $\begin{array}{l}\mathrm{Hb} \text { at } 6 \\
\text { months }\end{array}$ & 199 & $\begin{array}{l}10.84 \pm \\
0.88\end{array}$ & \multirow[t]{2}{*}{-0.50} & 204 & $\begin{array}{l}10.96 \pm \\
0.90\end{array}$ & \multirow[t]{2}{*}{-0.54} & \multirow[t]{2}{*}{$\begin{array}{l}-0.01(-0.26- \\
0.28)\end{array}$} \\
\hline $\begin{array}{l}\mathrm{Hb} \text { at } 12 \\
\text { months }\end{array}$ & 190 & $\begin{array}{l}10.36 \pm \\
1.26\end{array}$ & & 201 & $\begin{array}{l}10.42 \pm \\
1.30\end{array}$ & & \\
\hline \multicolumn{8}{|c|}{ Subgroup of children with no anemia at 6 months } \\
\hline $\begin{array}{l}\mathrm{Hb} \text { at } 6 \\
\text { months }\end{array}$ & 88 & $\begin{array}{l}11.61 \pm \\
0.41\end{array}$ & \multirow[t]{2}{*}{-0.70} & 101 & $\begin{array}{l}11.68 \pm \\
0.55\end{array}$ & \multirow[t]{2}{*}{-0.62} & \multirow[t]{2}{*}{$\begin{array}{l}-0.08(-0.38- \\
0.23)\end{array}$} \\
\hline $\begin{array}{l}\mathrm{Hb} \text { at } 12 \\
\text { months }\end{array}$ & 84 & $\begin{array}{l}10.90 \pm \\
1.03\end{array}$ & & 99 & $\begin{array}{l}11.05 \pm \\
1.09\end{array}$ & & \\
\hline \multicolumn{8}{|c|}{ Subgroup of children with mild anemia at 6 months ${ }^{\# \S}$} \\
\hline $\begin{array}{l}\mathrm{Hb} \text { at } 6 \\
\text { months }\end{array}$ & 85 & $\begin{array}{l}10.51 \pm \\
0.28\end{array}$ & \multirow[t]{2}{*}{-0.44} & 77 & $\begin{array}{l}10.52 \pm \\
0.32\end{array}$ & \multirow[t]{2}{*}{-0.41} & \multirow[t]{2}{*}{$\begin{array}{l}-0.03(-0.37- \\
0.31)\end{array}$} \\
\hline $\begin{array}{l}\mathrm{Hb} \text { at } 12 \\
\text { months }\end{array}$ & 84 & $\begin{array}{l}10.08 \pm \\
1.23\end{array}$ & & 76 & $\begin{array}{l}10.08 \pm \\
1.10\end{array}$ & & \\
\hline \multicolumn{8}{|c|}{ Subgroup of children with moderate anemia at 6 months ${ }^{\# \S}$} \\
\hline $\begin{array}{l}\mathrm{Hb} \text { at } 6 \\
\text { months }\end{array}$ & 26 & $\begin{array}{l}9.31 \pm \\
0.56\end{array}$ & \multirow[t]{2}{*}{0.11} & 26 & $9.49 \pm 0.33$ & \multirow[t]{2}{*}{-0.51} & \multirow[t]{2}{*}{$\begin{array}{l}0.62(0.02- \\
1.22)^{\star \star}\end{array}$} \\
\hline $\begin{array}{l}\mathrm{Hb} \text { at } 12 \\
\text { months }\end{array}$ & 22 & $\begin{array}{l}9.34 \pm \\
1.26\end{array}$ & & 26 & $8.98 \pm 1.04$ & & \\
\hline \multicolumn{8}{|c|}{ Changes in transferrin saturation (TSAT) levels, \% } \\
\hline $\begin{array}{l}\text { TSAT at } 6 \\
\text { months }\end{array}$ & 199 & $\begin{array}{l}12.1(7.89- \\
15.9)\end{array}$ & -2.36 & 204 & $\begin{array}{l}10.9(7.9- \\
15.45)\end{array}$ & -2.10 & $\begin{array}{l}-0.26(-1.89 \\
1.36)\end{array}$ \\
\hline $\begin{array}{l}\text { TSAT at } 12 \\
\text { months }\end{array}$ & 189 & $\begin{array}{l}7.9(5.9- \\
13.3)\end{array}$ & & 201 & $\begin{array}{l}8.1(5.8- \\
11.7)\end{array}$ & & \\
\hline \multicolumn{8}{|c|}{ Change in 25-Hydroxy vitamin D (25-OH-D) levels, ng/ml } \\
\hline $\begin{array}{l}25 \mathrm{OHD} \text { at } 6 \\
\text { months }\end{array}$ & 199 & $\begin{array}{l}20.4(13.7- \\
29)\end{array}$ & 1.46 & 204 & $\begin{array}{l}20.85(12- \\
30.05)\end{array}$ & -0.18 & $\begin{array}{l}1.63(-0.52- \\
3.78)^{@}\end{array}$ \\
\hline $\begin{array}{l}250 \mathrm{HD} \text { at } \\
12 \text { months }\end{array}$ & 189 & $\begin{array}{l}23.7(17.6- \\
30.4)\end{array}$ & & 201 & $\begin{array}{l}21.80(16.9- \\
27.9)\end{array}$ & & \\
\hline
\end{tabular}


$\$$ All values expressed as Mean +/- SD for normally distributed data and median (interquartile range) for data not normally distributed; \#No anemia ( $\mathrm{Hb}>11 \mathrm{gm} \%)$, Mild ( $\mathrm{Hb} 10-11 \mathrm{gm} \%)$, Moderate (Hb 7-<10 $\mathrm{gm} \%)$, Severe $(\mathrm{Hb}<7 \mathrm{gm} \%)$; *Parameters adjusted for compliance to the intervention, concomitant administration of nutritional supplements containing iron/vitamin $D ; * \star p=0.043$, @= 0.049; § - Subgroup analysis additionally adjusted for gender, weaning age and maternal education

The intervention of LMF oil resulted in significantly increased 25-OHD levels at 12 months in the LMF oil group as compared to a decrease in 25-OHD levels in the placebo group after adjusting for intake of concomitant oral vitamin D supplements $[1.46 \mathrm{ng} / \mathrm{ml} \mathrm{vs.}-0.18 \mathrm{ng} / \mathrm{ml}, \mathrm{p}=0.049$ ] [Table 2 \& Figure $3 \mathrm{~b}$ ]. At 12 months, the proportion of children with vitamin D insufficiency ( $25-\mathrm{OHD}$ levels $<20 \mathrm{ng} / \mathrm{ml}$ ) reduced by $14.38 \%$ in the intervention group as compared to a $7.24 \%$ decrease in the placebo group $(p=0.07)$ [Figure2b].

There was no significant difference in the mental DQ between the groups at 12 months of age [Median(IQR); 107.49(92.93-108.38)in the LMF oil group vs. 107.57(99.66-108.38) in placebo; $p=0.56$ ]. Similarly, motor DQs were comparable between the groups at 12 months of age [Median(IQR); 108.56(99.09-109.57) in the LMF oil group vs. 108.49(99.25-109.66) in placebo; $p=0.58$ ] [Figure 4].

During subgroup analysis for individual clusters of motor development, children in the LMF oil group were rated significantly better for the social interaction cluster as compared to the placebo group. In the subgroup of children with vitamin D insufficiency, the motor developmental quotient was significantly higher in the LMF oil group as compared to placebo[Table 3]. There were no significant differences for mental developmental quotient in the subgroup analysis [Data not shown].

Table 3: Odds ratios for more than median ( $50^{\text {th }}$ centile) developmental score 


\begin{tabular}{|c|c|c|c|c|}
\hline Parameter & $\mathbf{N}$ & OR for placebo oil & OR for LMF oil & $95 \% \mathrm{Cl}$ \\
\hline Motor DQ\# & 391 & 1 & 1.09 & $0.73-1.64$ \\
\hline Mental DQ\# & 391 & 1 & 0.97 & $0.65-1.44$ \\
\hline \multicolumn{5}{|l|}{ Subgroup analysis for motor $\mathrm{DQ}^{\$}$} \\
\hline \multicolumn{5}{|l|}{ Haemoglobin at 6 months } \\
\hline No anaemia & 182 & 1 & 1.04 & $0.56-1.95$ \\
\hline Mild anaemia & 155 & 1 & 1.72 & $0.85-3.50$ \\
\hline Moderate anaemia & 48 & 1 & 0.64 & $0.15-2.80$ \\
\hline \multicolumn{5}{|l|}{ Transferrin saturation at 6 months } \\
\hline TSAT<16\% & 299 & 1 & 1.09 & $0.68-1.76$ \\
\hline TSAT $>16 \%$ & 88 & 1 & 1.10 & $0.43-2.83$ \\
\hline \multicolumn{5}{|l|}{ Vitamin D levels at 6 months } \\
\hline Sufficient ( $\geq 20 \mathrm{ng} / \mathrm{ml}$ ) & 202 & 1 & 0.83 & $0.46-1.49$ \\
\hline Insufficient (12-20 ng/ml) & 102 & 1 & 3.38 & $1.30-8.82^{\star}$ \\
\hline Inadequate $(<12 \mathrm{ng} / \mathrm{ml})$ & 83 & 1 & 0.66 & $0.24-1.82$ \\
\hline \multicolumn{5}{|l|}{ Analysis for individual clusters of DASII } \\
\hline Social interaction & 390 & 1 & 1.51 & $1.00-2.29 * *$ \\
\hline Locomotion: Coordinated movements & 390 & 1 & 1.02 & $0.66-1.58$ \\
\hline Language and vocabulary & 390 & 1 & 1.25 & $0.81-1.94$ \\
\hline Body control & 390 & 1 & 1.55 & $0.73-3.28$ \\
\hline
\end{tabular}

$* p=0.013, * * p=0.047 ; \#$ Multiple logistic regression adjusted for concomitant medicines and compliance.

\$ For subgroups, analysis additionally adjusted for gender, weaning age, and maternal education

The anthropometric parameters were comparable between the groups at all timepoints except that the head circumference of children in the LMF oil group was significantly greater than the placebo group at baseline. The average age of weaning was approximately 6 months in both the groups [Additional Table3]. 
The local and systemic adverse events were not significantly different between the groups [Additional Table 4].

\section{Discussion}

This was the first proof-of-concept study to assess the benefit of liposomal micronutrient fortified oil in the prevention of nutritional deficiencies and improvement in neurodevelopment.

Our study showed that the use of LMF oil for infant massage did not significantly prevent nutritional anemia, however, showed some protection against anemia in children with moderate anemia at 6 months of age. The composition of LMF oil was based on the recommended daily amounts of absorbed elemental iron and other nutrients for the given age and based on available in vitro as well as in vivo evidence. Higher than recommended daily amounts were not used to avoid the risk of toxicity. Further, absorption of iron is dependent upon the iron stores in the body, thus the absorption from the oral route is increased in deficiency states(35). Although there is no clear evidence about the regulation of the mechanism of absorption of iron through the transdermal route, this may probably explain the improvement in hemoglobin levels in the moderate anemia subgroup.

There was a significant improvement in 25-OHD levels in the LMF oil group as compared to the placebo group. Vitamin D is fat-soluble and the lipophilic nature of the molecule facilitates liposomal encapsulation and transcutaneous absorption(36). An earlier pilot study amongst female medical students has shown a significant increase in serum 25-OHD levels following topical application of a cream containing vitamin $\mathrm{D}$, however, the doses used in the cream were much higher than the recommended dietary intake(37).

The intervention of LMF oil did not result in significant improvement in the overall mental and motor developmental quotient. There is equivocal literature about the effect of iron supplements on cognitive and motor development in children under 2-3 years(2) and more long-term studies are needed in this regard. Nutritional interventions such as zinc, vitamin A, folate, or multiple micronutrients have been shown to have a small effect on mental development $(8,38)$. In the present study, as the intervention did not result in significant improvement in nutritional anemia, the effect of the intervention on neurodevelopment through the reduction in anemia cannot be interpreted.

There was an improvement in the motor quotient after the intervention within the subgroup of insufficient vitamin D. Observational studies have shown an inconsistent association of 25-OHD with neurobehavioural outcomes. There is a lack of evidence from randomized controlled studies that address this issue. Recent findings from a small study in 55 infants have shown a beneficial effect of oral vitamin D3 $400 \mathrm{IU}$ on gross motor development. However, this effect was not found to be dose-dependent as only a low dose was associated with the benefit(39). It would be important to assess whether higher doses of vitamin $\mathrm{D}$ would provide significant benefits in vitamin $\mathrm{D}$ deficient children. 
The study showed significant improvement in social interaction in the LMF oil group. Studies in preschool children have shown that iron deficiency anemia is associated with altered affect and behaviour (40) as well as poor externalizing behaviour(41). However, as the intervention of LMF oil did not significantly improve hemoglobin levels in the overall population, whether this effect was independent of improvement in anemia status remains to be understood.

The use of LMF oil was not found to be associated with increased gastrointestinal adverse effects as compared to placebo, unlike oral iron (42). There was no significant increase in the rashes or pigmentation or skin infection with almost year-long use of LMF oil. However, there was a non-significant increase in the risk of respiratory infections with the use of LMF oil [Additional table 2].

One of the strengths of the study is that it used a traditional age-old custom of an infant oil massage to deliver the intervention of micronutrients to babies and demonstrated very good compliance to the intervention (around 96\%). This could be due to the social acceptability of infant oil massage in Indian rural communities. The study evaluated a technology paired with social innovation in a public health setup. The innovation has used only biodegradable GRAS-approved materials thus improving its acceptability and tolerability while use in infants. The cost of manufacturing LMF oil was minimal (approx. $1 \$$ for $90 \mathrm{ml}$ ) and the oils were stable at room temperature making it suitable for large-scale public use.

The study has several limitations. Although it was feasible to implement infant massage for 12 months in our study, in routine practice, infant massage is not regularly implemented in older infants and toddlers. (43). It may also be challenging to administer oil massage to older infants due to their increased movement. Further, traditionally oil massage is administered to the babies in the morning before bath. It was hypothesized that this would not have allowed adequate time for the absorption of nutrients from the LMF oil. This limitation was overcome by requesting the caregivers to administer the oil at bedtime.

The nutrition status of breastfeeding infants is dependent on the maternal intake of nutrients which was not collected during the study. Vitamin $D$ levels are affected by the duration and intensity of sun exposure which was not collected during the study. Ferritin and soluble transferrin receptor levels which are better indicators of iron stores and iron deficiency than hemoglobin and transferrin were not measured due to logistic constraints and the analysis for anemia were not adjusted for inflammatory markers like Creactive proteins. Vitamin B12 and folate may have played a role in the developmental outcomes. However, this study has not measured changes in the plasma levels of folate and B12. Despite the lack of overall efficacy, this is the first scientific attempt in assessing iron delivery through the skin in a clinical study. Results of the study show that vitamin $D$ due to its lipophilic nature is more suitable for transdermal delivery than iron. The transdermal delivery of iron needs to be studied using more mechanistic human studies to assess cutaneous pharmacokinetics of the liposomal encapsulated iron and in target populations with iron deficiency who are probably more iron-responsive than the healthy 
population. Also, the effect of increasing doses of nutrients needs to be studied for transdermal delivery.

\section{Conclusion}

The intervention of liposomal encapsulated micronutrient fortified oil for supplementing micronutrients to infants through body massage did not prevent anemia or improve neurodevelopment in Indian infants but prevented vitamin $\mathrm{D}$ deficiency to some extent with improvement in $25-\mathrm{OH}-\mathrm{D}$ at 12 months. In the subgroup of infants with moderate anemia, intervention prevented the decline in hemoglobin at 12 months of age. Future studies are needed to optimize the composition of oil and to assess the effect of increased doses.

\section{Declarations}

\section{Ethics approval and consent to participate}

This study was conducted in accordance with the international consortium for harmonization good clinical practices (ICH-GCP) and the ethical guidelines for biomedical research in India by the Indian Council of Medical Research (ICMR).

The study was approved by the institutional ethics committee of KEM Hospital Research Centre (KEMHRC/LFG/EC/146), Pune, India on 18/04/2017. Written informed consent was obtained from the the parents/legal guardians of all study participants.

\section{Consent for publication:}

Not applicable

\section{Funding:}

This project was funded through Saving Brains platform, Grand Challenges Canada [Grant number: 17070895].

\section{Availability of data and materials:}

The datasets used and/or analysed during the current study are available from the corresponding author on reasonable request.

\section{Conflict of interest:}


None

\section{Acknowledgements}

We would like to thank Jayeeta Pahan [Murli Krishna Pharmaceuticals] for manufacturing the test and placebo oil under GMP conditions. We would like to thank Ujjwal Nene [TDH Centre, KEM Hospital] for her support in training for DASIl assessment, Girish Dayma [Vadu Rural Health Program, KEM Hospital Research Centre] for his support in field management, and Tathagata Bhattacharjee [Vadu Rural Health Program, KEM Hospital Research Centre] for data management services. We would like to thank all the

field research assistants from Vadu Rural Health Program who helped in data acquisition. We are in debt to all the study participants and their family members for agreeing to participate in this study and providing their valuable data.

\section{Author contribution}

$A A, A B, R B, S R$, SJ designed the research. $A A, M K, S N, H L, D S, P K, D A, A K, R B, S J, A B$ conducted the research. $A A, M K, S N, H L$ provided the required materials /reagents. $A A, M K$, and $R B$ validated the technology for intervention. AA,SR analysed data and performed statistical analysis. AA and HL wrote paper. $A B$ and $R B$ had primary responsibility for final conduct.

\section{Abbreviations}

LMF oil - liposomal micronutrient fortified oil

KEM Hospital - King Edward Memorial Hospital

SRL - Super Religare Laboratories

GRAS - Generally recognized as safe

EuGMP - European Good Manufacturing Conditions

DASII - Developmental assessment scale for Indian Infants

EDTA - Ethylenediaminetetraacetic acid

TSAT - Transferrin saturation levels

25-OHD - 25-Hydroxy vitamin D

TIBC - Total iron binding capacity

eCRF - electronic case record form 
Hb- Hemoglobin

DQ - Developmental quotient

\section{References}

1. John CC, Black MM, Nelson CA. Neurodevelopment: The impact of nutrition and inflammation during early to middle childhood in low-resource settings. Pediatrics. 2017;139(April 2017):S59-71.

2. Lozoff B. Iron deficiency and child development. Food and Nutrition Bulletin. 2007;28(4 SUPPL.):560-71.

3. Black MM. Effects of vitamin B12 and folate deficiency on brain development in children. Food and nutrition bulletin. 2008 Jun;29(2 Suppl):S126-31.

4. Winje BA, Kvestad I, Krishnamachari S, Manji K, Taneja S, Bellinger DC, et al. Does early Vitamin B12 supplementation improve neurodevelopment and cognitive function in childhood and into school age: A study protocol for extended follow-ups from randomised controlled trials in India and Tanzania. BMJ Open. 2018;8(2).

5. Gao Y, Sheng C, Xie RH, Sun W, Asztalos E, Moddemann D, et al. New perspective on impact of folic acid supplementation during pregnancy on neurodevelopment/autism in the offspring children - $A$ systematic review. PLoS ONE. 2016;11(11):1-16.

6. Anjum I, Jaffery SS, Fayyaz M, Samoo Z, Anjum S. The Role of Vitamin D in Brain Health: A Mini Literature Review. Cureus. 2018;10(7).

7. Larson LM, Phiri KS, Pasricha SR. Iron and Cognitive Development: What Is the Evidence? Annals of Nutrition and Metabolism. 2017;71(3):25-38.

8. Kvestad I, Taneja S, Kumar T, Hysing M, Refsum H, Yajnik CS, et al. Vitamin B12 and Folic Acid Improve Gross Motor and Problem-Solving Skills in Young North Indian Children: A Randomized PlaceboControlled Trial. PloS one. 2015;10(6):e0129915.

9. International Institute for Sciences. National Family Health Survey - 4: 2015-16, India Fact sheet. In: National Family Health Survey - 4: 2015-16. Ministry of Health and Family Welfare, Government of India; 2016. p. 1-6.

10. Aparna P, Muthathal S, Nongkynrih B, Gupta SK. Vitamin D deficiency in India. Journal of family medicine and primary care. 2018;7(2):324-30.

11. Suchdev PS, Ruth LJ, Woodruff BA, Mbakaya C, Mandava U, Flores-Ayala R, et al. Selling Sprinkles micronutrient powder reduces anemia, iron deficiency, and vitamin A deficiency in young 
children in Western Kenya: a cluster-randomized controlled trial. The American journal of clinical nutrition. 2012 May;95(5):1223-30.

12. Fouelifack FY, Sama JD, Sone CE. Assessment of adherence to iron supplementation among pregnant women in the Yaounde gynaeco-obstetric and paediatric hospital. The Pan African medical journal. 2019;34:211.

13. Galloway R, McGuire J. Determinants of compliance with iron supplementation: supplies, side effects, or psychology? Social science \& medicine (1982). 1994 Aug;39(3):381-90.

14. Mahalhal A, Williams JM, Johnson S, Ellaby N, Duckworth CA, Burkitt MD, et al. Oral iron exacerbates colitis and influences the intestinal microbiome. PLoS ONE. 2018;13(10):1-18.

15. Stoffel NU, Cercamondi Cl, Brittenham G, Zeder C, Geurts-Moespot AJ, Swinkels DW, et al. Iron absorption from oral iron supplements given on consecutive versus alternate days and as single morning doses versus twice-daily split dosing in iron-depleted women: two open-label, randomised controlled trials. The Lancet Haematology. 2017 Nov;4(11):e524-33.

16. Jijie R, Barras A, Boukherroub R, Szunerits S. Nanomaterials for transdermal drug delivery: Beyond the state of the art of liposomal structures. Journal of Materials Chemistry B. 2017;5(44):8653-75.

17. Prow TW, Grice JE, Lin LL, Faye R, Butler M, Becker W, et al. Nanoparticles and microparticles for skin drug delivery. Advanced drug delivery reviews. 2011 May;63(6):470-91.

18. Banerjee R. Overcoming the stratum corneum barrier: a nano approach. Drug Delivery and Translational Research. 2013 Jun;3(3):205-8.

19. Maghbool M, Khosravi T, Vojdani S, Chaijan MR, Esmaeili F, Amani A, et al. The effects of eugenol nanoemulsion on pain caused by arteriovenous fistula cannulation in hemodialysis patients: A randomized double-blinded controlled cross-over trial. Complementary therapies in medicine. 2020 Aug;52:102440.

20. Xu W, Li Y, Ju M, Lai W, Lu X, Shi H, et al. A Multicenter, Randomized, Double-Blind, PlaceboControlled Study of Compound Glycyrrhizin Capsules Combined with a Topical Corticosteroid in Adults with Chronic Eczema. Capasso R, editor. Evidence-Based Complementary and Alternative Medicine 2020;2020:6127327.

21. Rinti Banerjee (Department of Biosciences and Bioengineering II of T. Nanoparticle-based cosmetic composition. India: Indian Patent office; 2695/MUM/2011. Available from: https://ipindiaservices.gov.in/PublicSearch/PublicationSearch/PatentDetails [accessed 27 May 2021]

22. Rinti Banerjee (Department of Biosciences and Bioengineering II of T. Nanoparticle-based cosmetic composition. United States Patent Office; US 9,375,388 B2. Available from: 
https://patentimages.storage.googleapis.com/88/3f/d3/b86fe03a89223b/US9375388.pdf accessed 27 May 2021.

23. Kapoor MS, D'Souza A, Aibani N, Nair SS, Sandbhor P, Kumari D, et al. Stable Liposome in Cosmetic Platforms for Transdermal Folic acid delivery for fortification and treatment of micronutrient deficiencies. Scientific reports. 2018 Oct;8(1):16122.

24. Apte A, Lubree H, Kapoor M, Juvekar S, Banerjee R BA. Development and implementation of liposomal encapsulated micronutrient fortified body oil intervention for infant massage: an innovative concept to prevent micronutrient deficiencies in children. Frontiers in public health. 2020;8:1095. doi: 10.3389/fpubh.2020.567689.

25. Sanity Lifesciences Pvt Ltd. Observational Study of safety evaluation of 5 cosmetic formulations on 26 healthy human subjects. 2018.

26. Li X, Zhong Q, Tang L. A Meta-Analysis of the Efficacy and Safety of Using Oil Massage to Promote Infant Growth. Journal of pediatric nursing. 2016;31(5):e313-22.

27. Patil R, Roy S, Ingole V, Bhattacharjee T, Chaudhary B, Lele P, et al. Profile: Vadu Health and Demographic Surveillance System Pune, India. Journal of global health. 2019 Jun;9(1):10202.

28. Orsavova J, Misurcova L, Vavra Ambrozova J, Vicha R, Mlcek J. Fatty acids composition of vegetable oils and its contribution to dietary energy intake and dependence of cardiovascular mortality on dietary intake of fatty acids. International Journal of Molecular Sciences. 2015;16(6):12871-90.

29. Khadilkar A, Khadilkar V, Chinnappa J, Rathi N, Khadgawat R, Balasubramanian S, et al. Prevention and treatment of vitamin $D$ and calcium deficiency in children and adolescents: Indian Academy of Pediatrics (IAP) guidelines. Indian Pediatrics. 2017;54(7):567-73.

30. National Institute of Nutrition. Nutrient Requirements and Recommended Dietary Allowances for Indians a. Report of the Expert Group of the Indian Council of Medical Research . 2009;1-334. Available from: http://ninindia.org/DietaryGuidelinesforNINwebsite.pdf [accessed 27 May 2021]

31. Phatak P, Dhapre M, Pandit AN, Kulkarni S. A study of Baroda Development Screening Test for infants. Vol. 28, Indian pediatrics. 1991. p. 843-9.

32. Brett D. An evaluation of a variety of skin care formulations on children 0 to 36 months of age with normal skin. Journal of Wound, Ostomy \& Continence Nursing. 2011;38:S77-S77.

33. Carpenter CE, Ward RE. Iron Determination by Ferrozine Method. In: Food Analysis Laboratory Manual. Cham: Springer International Publishing; 2017. p. 157-9.

34. Hutchinson K, Healy M, Crowley V, Louw M, Rochev Y. Verification of Abbott 25-OH-vitamin D assay on the architect system. Practical laboratory medicine. 2017 Apr;7:27-35. 
35. Wallace DF. The Regulation of Iron Absorption and Homeostasis. Clin Biochem Rev. 2016;37(2):51-62.

36. Sawarkar S, Ashtekar A. Transdermal vitamin D supplementation-A potential vitamin D deficiency treatment. Journal of cosmetic dermatology. 2020 Jan;19(1):28-32.

37. Sadat-Ali M, Bubshait DA, Al-Turki HA, Al-Dakheel DA, Al-Olayani WS. Topical delivery of vitamin d3: a randomized controlled pilot study. International journal of biomedical science: IJBS. 2014 Mar;10(1):21-4.

38. Black MM. Micronutrient deficiencies and cognitive functioning. The Journal of nutrition. 2003 Nov;133(11 Suppl 2):3927S-3931S.

39. Wicklow B, Gallo S, Majnemer A, Vanstone C, Comeau K, Jones G, et al. Impact of Vitamin D Supplementation on Gross Motor Development of Healthy Term Infants: A Randomized Dose-Response Trial. Physical \& occupational therapy in pediatrics. 2016 Aug;36(3):330-42.

40. Lozoff B, Corapci F, Burden MJ, Kaciroti N, Angulo-Barroso R, Sazawal S, et al. Preschool-Aged Children with Iron Deficiency Anemia Show Altered Affect and Behavior. The Journal of Nutrition 2007;137(3):683-9.

41. Su J, Cui N, Zhou G, Ai Y, Sun G, Zhao SR, et al. Hemoglobin Status and Externalizing Behavioral Problems in Children. International journal of environmental research and public health. $2016 \mathrm{Jul} ; 13(8)$.

42. Simonyté Sjödin K, Domellöf M, Lagerqvist C, Hernell O, Lönnerdal B, Szymlek-Gay EA, et al. Administration of ferrous sulfate drops has significant effects on the gut microbiota of iron-sufficient infants: a randomised controlled study. Gut [Internet]. 2019 Nov 1;68(11):2095 LP - 2097.

43. Domellof M. Iron requirements in infancy. Annals of nutrition \& metabolism. 2011;59(1):59-63.

\section{Figures}




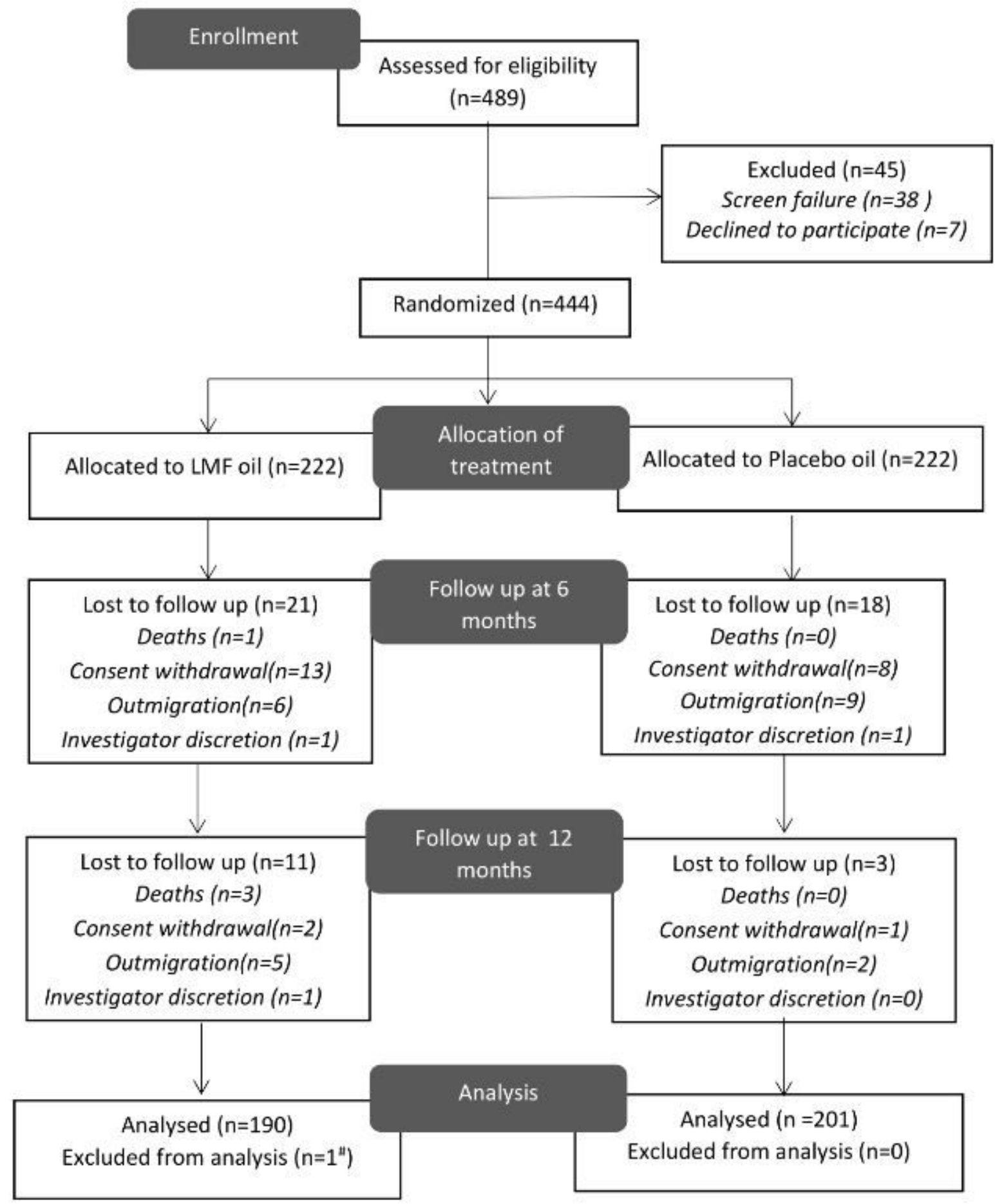

\section{Figure 1}

Study flow chart 


\section{$2 a$}

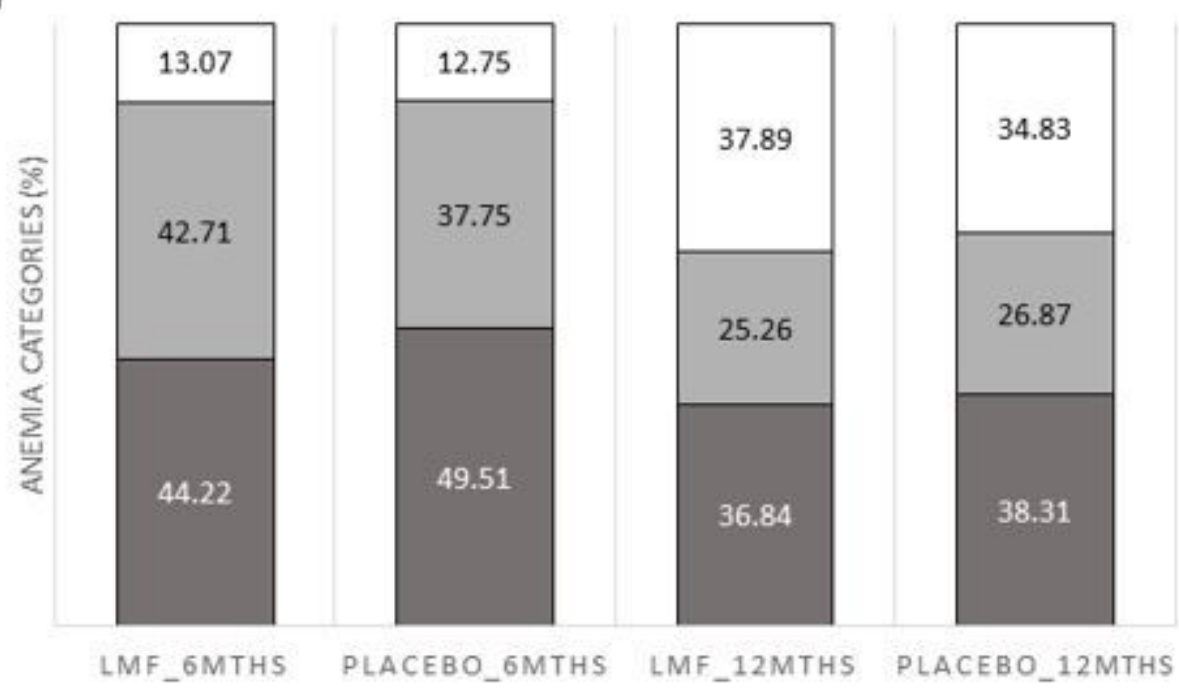

$\square$ No Anemia $\quad \square$ Mild Anemia $\square$ Moderate Anemia

\section{$2 b$}

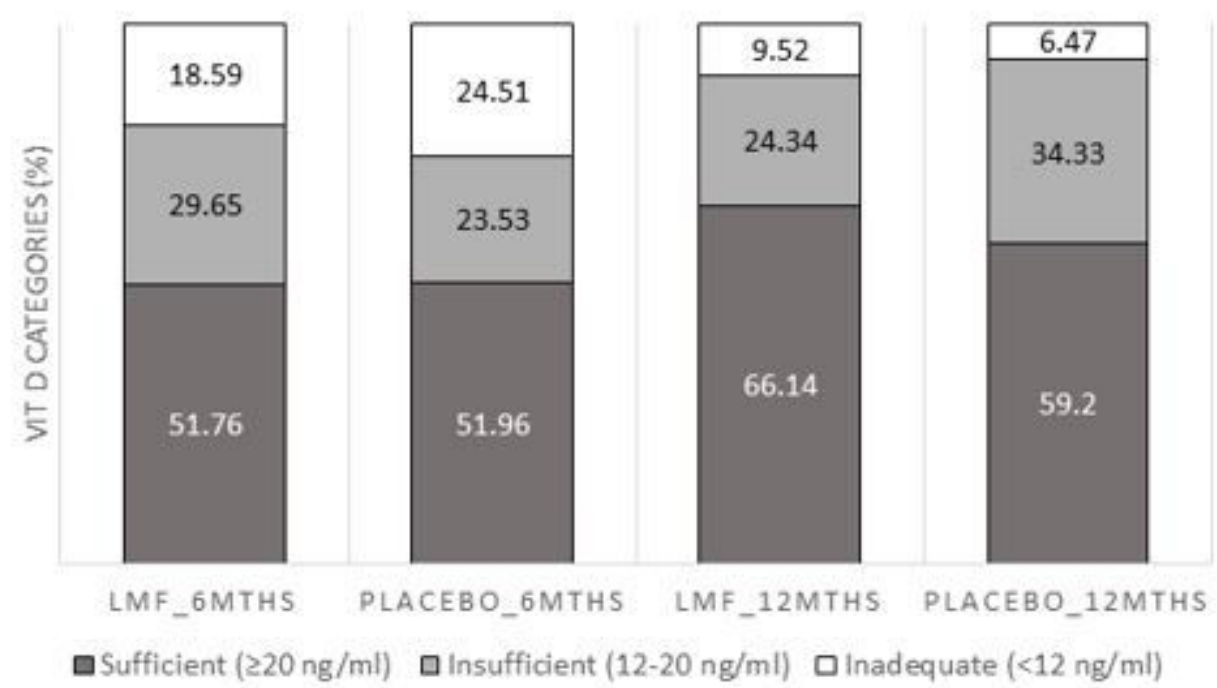

\section{Figure 2}

Distribution of anemia and vitamin D deficiency at 6 months and 12 months in LMF oil and placebo groups 2a: Children with no anemia, mild anemia, and moderate anemia at 6 and 12 months [Mild ( $\mathrm{Hb}$ 10-11 gm\%), Moderate ( $\mathrm{Hb} 7-<10 \mathrm{gm} \%)$, Severe ( $\mathrm{Hb}<7 \mathrm{gm} \%)]$; 2b: Children with vitamin D sufficiency, insufficiency, and adequacy at 6 months and 12 months [25-OHD levels - Sufficient ( $\geq 20 \mathrm{ng} / \mathrm{ml}$ ); Insufficient (12-20 ng/ml); Inadequate ( $<12 \mathrm{ng} / \mathrm{ml})$ ] 

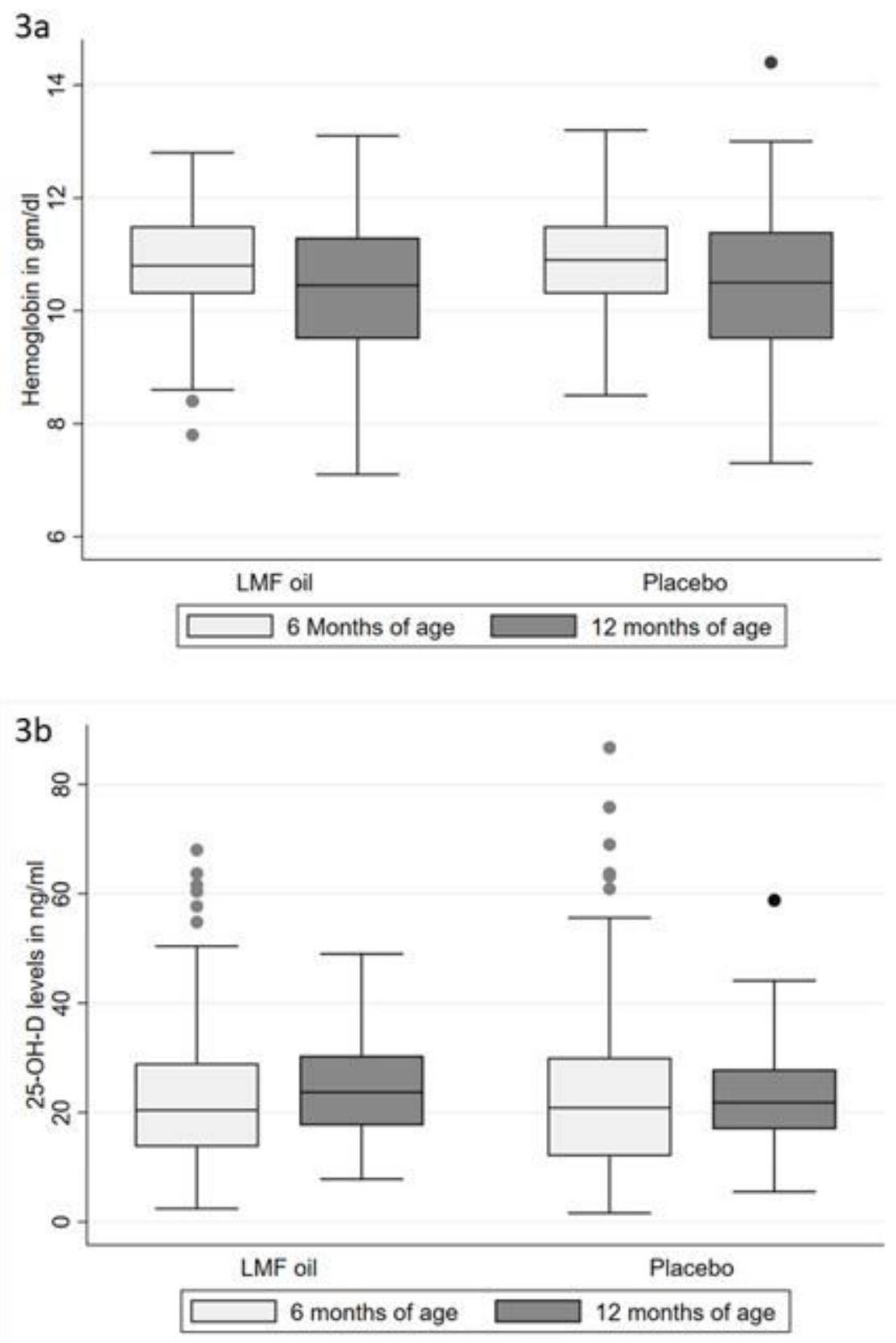

Figure 3

Change in hemoglobin (in subgroup of children with moderate anemia at 6 months) and 25-hydroxy vitamin D levels (overall) in LMF oil and placebo group 3a: Change in hemoglobin levels in the subpopulation of infants with moderate anemia $(\mathrm{Hb}>7<10 \mathrm{gm} / \mathrm{dl})$ at 6 months $3 \mathrm{~b}$ : Change in 25-hydroxy vitamin D levels in LMF oil and placebo group 


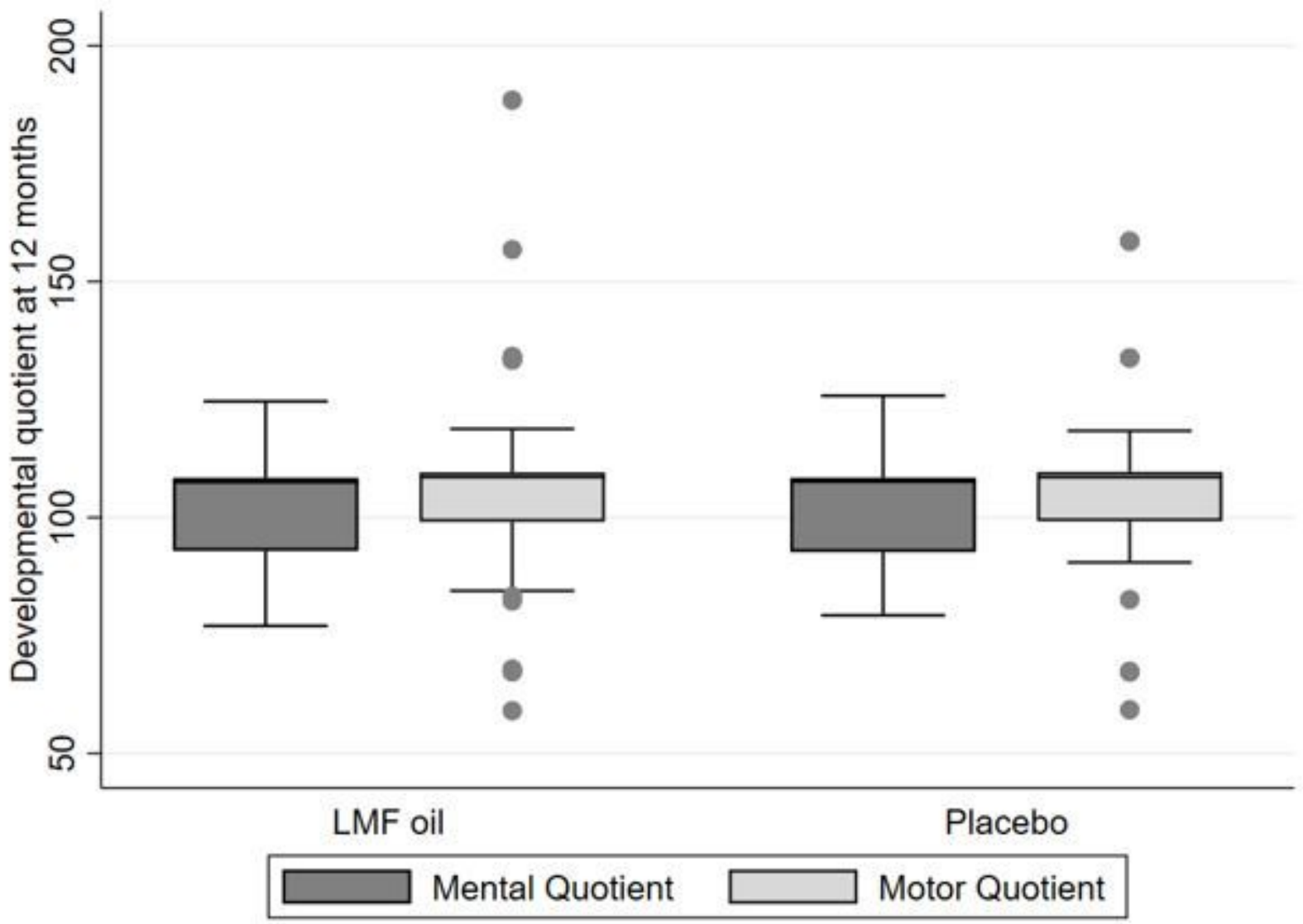

Figure 4

Developmental assessment at 12 months using DASII\# DASII- developmental assessment of Indian infants During subgroup analysis for individual clusters of motor development, children in the LMF oil group were rated significantly better for the social interaction cluster as compared to the placebo group. In the subgroup of children with vitamin D insufficiency, the motor developmental quotient was significantly higher in the LMF oil group as compared to placebo[Table 3]. There were no significant differences for mental developmental quotient in the subgroup analysis [Data not shown].

\section{Supplementary Files}

This is a list of supplementary files associated with this preprint. Click to download.

- Supplementarymaterial.docx 